\title{
Government changes are jeopardising public health
}

Prevention and early intervention are impossible without a strong and well equipped public health workforce

\author{
Delan Devakumar clinical lecturer in public health ${ }^{1}$, Kate $\mathrm{L}$ Mandeville specialty registrar in public \\ health ${ }^{2}$, Jennifer Hall specialty registrar in public health ${ }^{1}$, Shailen Sutaria specialty registrar in public \\ health ${ }^{3}$, Ingrid Wolfe clinical senior lecturer public health ${ }^{4}$
}

${ }^{1}$ University College London, London WC1E 6JB, UK; ${ }^{2}$ London School of Hygiene and Tropical Medicine, London, UK; ${ }^{3}$ Queen Mary University of London, London, UK; ${ }^{4}$ King's College London, London, UK

On some health markers, the United Kingdom compares well with similar countries - for example, access to health services. ${ }^{1}$ However, it fares poorly on many health risk factors, such as alcohol consumption and poor diet, and in some population outcomes such as child health. For example, the UK is 32 nd out of the 34 countries in the Organisation for Economic Cooperation and Development for childhood obesity. ${ }^{12}$ "Prevention is better than cure" is a central argument in the NHS Five Year Forward View strategy, yet the Health and Social Care Act 2012 and recent austerity budgets have reduced the power of public health as well as the specialist workforce, jeopardising the health of the public. ${ }^{3}$

\section{Reduced resources}

Under the Health and Social Care Act, English public health departments moved from the NHS to local authorities. Although this change brings some advantages, such as increasing the opportunity for coordination and integration of policies and services that affect determinants of health, there are also substantial drawbacks. Public health budgets were initially ringfenced, but this protection is likely to cease and pressure on these budgets will grow. Indeed, a BMA investigation showed that half of local authorities had used public health money for pre-existing services. ${ }^{4}$

Furthermore, whereas the NHS has nominal funding protection, public health budgets do not. The $£ 200 \mathrm{~m}(€ 255$; \$288) cuts in public health funding unexpectedly announced in June 2015 were in-year cuts and represented a $6.2 \%$ reduction in the annual public health budget. ${ }^{5}$ Further public health cuts of $3.9 \%$ a year till 2020 are also planned. ${ }^{6}$ Cuts are already being felt at the front line, with reductions in smoking cessation, sexual health, child health, and other services. ${ }^{78}$ Certain activities, such as health checks, are mandated, but even these do not have protected budgets. Cuts in local government and public health budgets affect people's health and wellbeing and will add to NHS pressures.

\section{Diminished public health workforce}

In addition to budget cuts, other new policies are adversely affecting the public health workforce's ability to improve the determinants of health. Morale in the public health workforce is low and $18 \%$ of director of public health positions were vacant in 2014. ${ }^{9}$ Filling public health roles with non-public health trained staff may save money but important skills are lost. Strong links between public health and the health service, underpinned by effective research, are vital for comprehensive strategies to improve health at a population level.

Moving public health away from the NHS has weakened those links, and the proposed new junior doctor contract will compound the problems among medically trained public health professionals and researchers. Doctors often enter public health after first training in another specialty. Dual trained staff are crucial for understanding the health service, managing notifiable diseases, and designing and evaluating effective health and care interventions. Research experience provides crucial skills for public health practice, such as appraising evidence to support decisions that affect large numbers of people. The new contract no longer recognises the valuable experience gained by public health doctors training in clinical specialties and discourages them from spending time in research during training. The risk is loss of knowledge, skills, and experience.

\section{Way forward}

We call for reinvestment in public health and protection of the workforce commensurate with the central role of public health in government policy. Further cuts to public health budgets will continue to hinder efforts to secure and improve health. Additionally, we need to attract the best people into the profession and encourage them to acquire important extra skills during training. In turn, we call on public health practitioners to publicise the benefits of their work. Public health has a central 
role in ensuring that interventions are evidence based, cost effective, and show measurable progress towards health outcomes. We need to renew our efforts to research and advocate for regulatory and legislative changes that will improve health. An excellent example of public health research and advocacy influencing policy is the recent announcement of the sugar tax. However, more needs to be done on alcohol, tobacco, physical activity, and other important determinants of disease and health. At a time when the population's health is at growing risk, ${ }^{10}$ recent actions have weakened the ability of public health professionals to respond. The changes are likely to lead to fewer jobs, held by people with a reduced skill mix and insufficient resources to work effectively. This is a clear contradiction of the government's commitment to tackling the determinants of poor health. Many of these problems were predicted during the debate leading to the introduction of the Health and Social Care Act, and alternatives were proposed that drew on lessons from history. ${ }^{11}$ While the virtues of prevention and early intervention are often broadcast, this is not possible without a strong and well equipped public health workforce working in effective partnership with the NHS. This is crucial if we are to improve the nation's health.

Competing interests: We have read and understood BMJ policy on declaration of interests and have no relevant interests to declare.
Provenance and peer review: Not commissioned; externally peer reviewed.

1 Wolfe I, Thompson M, Gill P, et al. Health services for children in western Europe. Lancet 2013;381:1224-34. doi:10.1016/S0140-6736(12)62085-6 pmid:23541056.

2 OECD. Health at a glance 2015. OECD, 2015.

3 NHS England. NHS five year forward view. NHS England, 2014.

4 British Medical Association. Local authorities plunder ringfenced public health funds 2015 http://www.bma.org.uk/news-views-analysis/news/2015/january/local-authorities-plunderringfenced-public-health-funds

5 Public Health Policy and Strategy Unit Department of Health. Local authority public health grant allocations 2015/16. Government response to public consultation on in-year savings and equality and health inequality analysis. 2015. www.gov.uk/government/uploads/ system/uploads/attachment_data/file/474135/Response_doc_acc.pdf.

6 Department of Health. Local authority circular: public health ring-fenced grant 2016/17 and 2017/18. DH, 2016

7 lacobucci G. Raiding the public health budget. BMJ 2014;348:g2274. doi:10.1136/bmj. g2274 pmid:24671967.

8 lacobucci G. Public health-the frontline cuts begin. BMJ 2016;532:i272. doi:10.1136/ bmj.i272 pmid:26791557.

9 Rimmer A. Labour raises concern over public health, with a fifth of director posts vacant. BMJ Careers 2014. http://careers.bmj.com/careers/advice/Labour_raises_concern_over_ public_health,_with_a_fitth_of_director_posts_vacant

10 Newton JN, Briggs AD, Murray CJ, et al. Changes in health in England, with analysis by English regions and areas of deprivation, 1990-2013: a systematic analysis for the Global Burden of Disease Study 2013. Lancet 2015;386:2257-74. doi:10.1016/S0140-6736(15) 00195-6 pmid:26382241.

11 McKee M, Hurst L, Aldridge RW, et al. Public health in England: an option for the way forward? Lancet 2011;378:536-9. doi:10.1016/S0140-6736(11)60241-9 pmid:21354610.

Published by the BMJ Publishing Group Limited. For permission to use (where not already granted under a licence) please go to http://group.bmj.com/group/rights-licensing/ permissions 